\title{
A CASE OF PRIMARY BILATERAL ANOPHTHALMIA (Clinical and Histological Report)
}

BY

\author{
Esmond RECORD(ON and GWENVRON M. GRIfFiths \\ CAMBRIDGE \\ LONDON
}

THE subject of this report, a male child, was born on November 13, 1935, at March, Cambridgeshire.

No case of developmental abnormality had occurred in the family of either parent, and there was no consanguinity. Pregnancy and labour had been normal.

The mother, a primipara, aged 31 years, was one of a family of six. Her eldest brother is healthy; an elder brother and sister survived only a few hours; whilst two younger sisters are alive and well. The elder of these has produced one healthy child; the younger's first child died in infancy; a second survives and is normal. Her father died at the age of 62 years; her mother is alive and well. One maternal aunt died in a mental home.

The father, aged 37 years, had been married twice previously. There were no issue by his first wife, but one healthy child by the second. He was the eldest of a family of six, all of whom survive and are normal except the third who died in infancy. One of his brothers has a healthy child. His father is alive and well, but his mother had died two years previously.

A normal child has since been born.

Dr. J. A. Hislop, of March, invited one of us (E.R.) to see the infant when thirty hours old. It appeared to be normal in every respect apart from the entire absence of eyes. The birth weight was $\tau$ lbs. 10 ozs. The eyelids were normal and the lacrymal puncta present. The palpebral apertures just admitted the tip of the little finger. Two smooth conjunctival sacs were explored but no vestige of a globe could be detected. The orbital cavities seemed to be smaller than normal.

The child progressed normally for a few days but later failed to put on weight, which on the tenth day was only $6 \frac{3}{4} \mathrm{lbs}$. Breast feeding was only possible for the first week. It was admitted to Addenbrooke's Hospital, Cambridge, under the care of Dr. Leslie Cole, and gained weight steadily until shortly before its death (January 8, 1936) from bronchopneumonia. A post-mortem was performed and the brain and orbits removed for microscopic examination. The only abnormal post-mortem findings, apart from those relating to the visual apparatus, were a patent foramen ovale (which measured 2 by 3 centimetres), and bronchopneumonic changes in the lungs. The thymus was normal in size and the testicles had descended to the scrotum. 
A detailed examination of half the brain and both orbits was made by one of us (G.M.G.) in the Pathological Laboratory, National Hospital, Queen Square, London :-

The brain appeared normal and well convoluted on its superior and lateral aspects. The base showed complete absence of the chiasma and optic tracts.

Serial sections in a frontal plane were made from the level of the olfactory trigone to the mid-pontine region and were stained for cells, myelin, neuroglia, and by silver impregnation for unmyelinated fibres. In these sections there was found no trace of optic tracts and nothing that could be identified as an external geniculate body. The hypothalamic region and infundibulum were intact with the nucleus paraventricularis and nuclei tuberis well marked. The supra-optic nucleus (Fig. 4), in the absence of an optic tract was lying flat, parallel to the meningeal surface and in one mass, instead of the normal two masses joined by a crescent of cells. The character of the cells and the vascularity appeared normal. The commissure of Meynert was well marked and well myelinated.

There was no abnormality of the basal ganglia, their fibre tracts, or of the internal capsule.

Between the mamillary bodies in the midline and projecting from the surface of the brain in a caudal direction was a teratoma 5 by $2 \mathrm{~mm}$. (Fig. 5). It consisted of several small cysts or globules, lined with squamous epithelium, and in relation to these some digitating glandular structures. Some of these were possibly early hair follicles. One very small cyst was lined with goblet-cell (intestinal) epithelium. The cysts were lying in a mass of fibrous tissue with nerve cells and fibres (often encircling the cysts), and a mass of cartilage. The arrangement of the cysts and cavities suggested a rudimentary eye (especially in one area which looked like an eyelid), but the absence of pigment and the presence of gut proved its teratomatous nature.

In the midbrain no abnormality was found. The anterior colliculus showed the normal strata, though the cells were immature. (This was true of most parts of the brain owing to the age of the child.) The nuclei of the cranial nerves, third, fourth, fifth, sixth, seventh and eighth were well marked and well differentiated, and their nerves well myelinated, as was the posterior longitutinal bundle. The pineal gland was normal.

Sections were made of the posterior part of the brain, including the calcarine region and the horn of the ventricle. The area striata (Fig. 6) was rather small, but showed a well marked line of Gennari ; the cells were mostly round and immature, but some were pyramidal in form. Silver impregnation showed the presence 
of nerve fibres in this region, but there was very little myelin, and optic radiations could not be identified.

The sphenoid bone (Fig. 3) was well formed except that the optic canals were not patent. Very small ophthalmic arteries appeared to terminate at the bony wall. The pituitary fossa and gland appeared normal. The orbits were rather small and seemed macroscopically to be filled with fat.

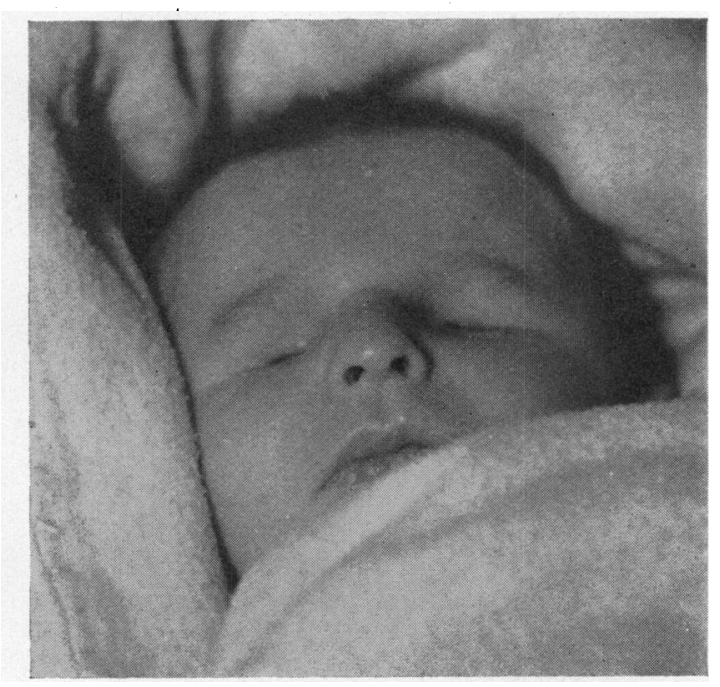

FIG. 1.

Anophthalmic baby, aged 5 weeks.

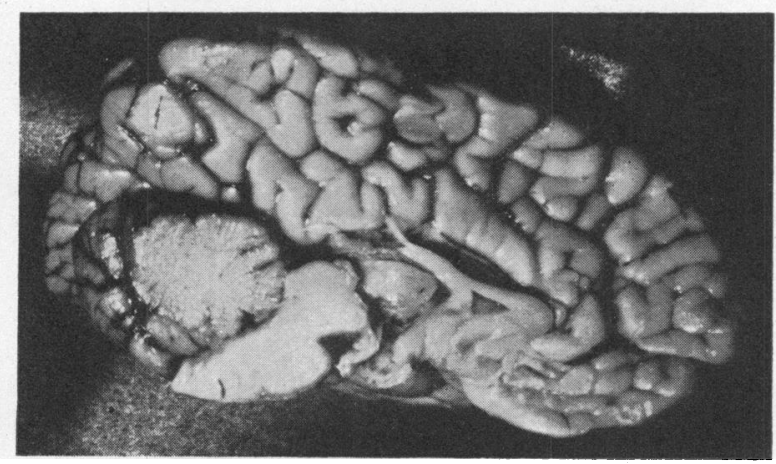

FIG. 2.

Medial aspect of brain. Showing absence of chiasma. 


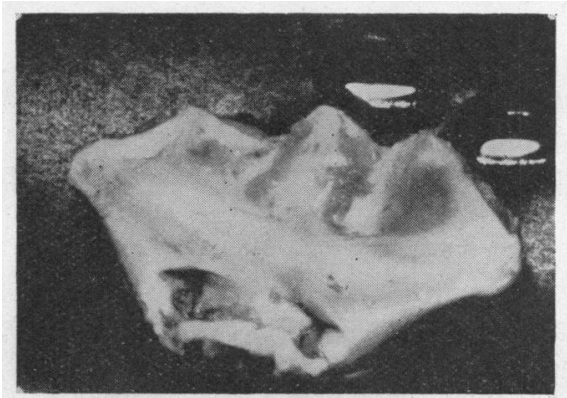

FIG. 3.

Sphenoid bone, showing ophthalmic arteries and flattening of bone over region of the optic foramina.

Nucleus supra-opticus, with the absence of optic tract.

FIG. 4

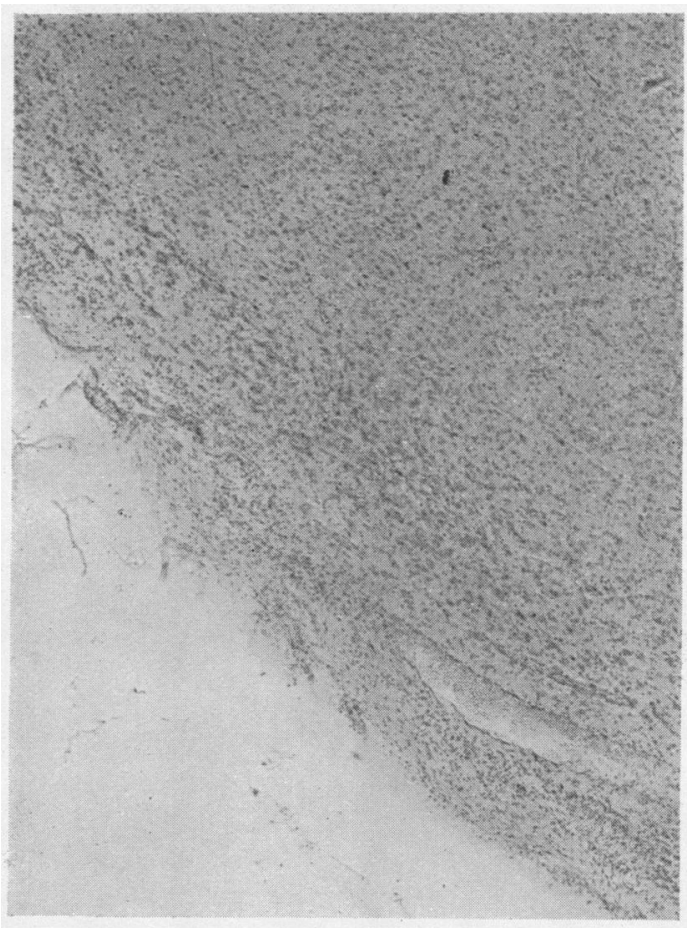


Serial sections were made of the left orbit vertically and of the right orbit horizontally. In both orbits the six extrinsic muscles and their nerves were found, embedded in fat.

The oblique muscles were lying along the bony wall. In the left orbit (Fig. 7) the four recti were lying parallel to each other in the fatty mass, and at the anterior end were attached to a minute

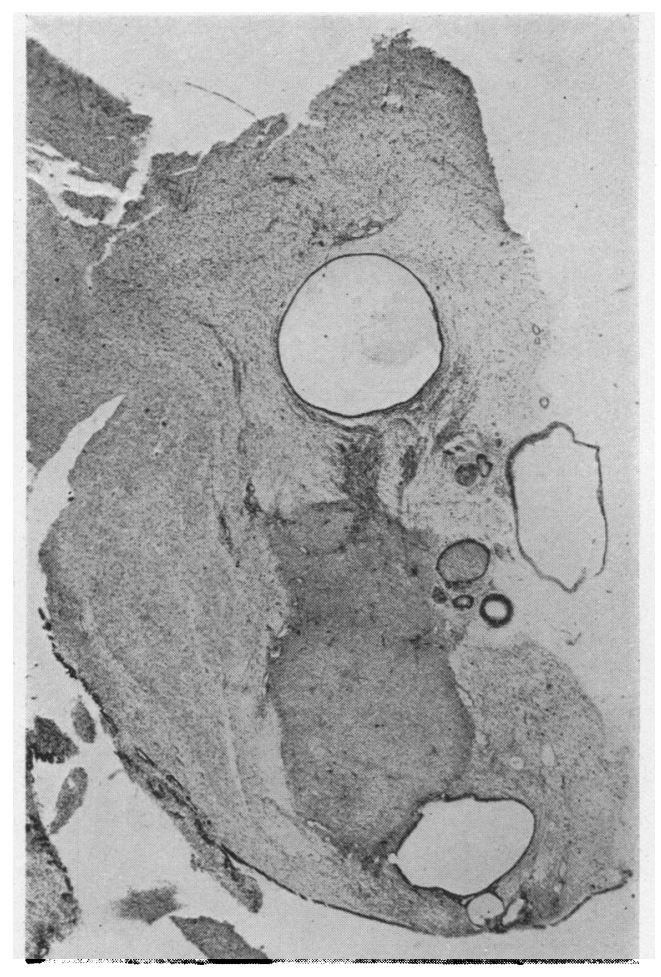

Fig. 5.

Teratoma in region of mammillary body.

nodule of fibrous tissue, 163 by 85 by 240 microns. This nodule contained a quantity of pigment granules apparently lying free and not contained in any recognisable cell structure. The pigment was brownish and did not give an iron reaction. On the right side a similar but more minute mass of fibrous tissue was found ( 56 by 38 by 210 microns) (Fig. 8 ), but the muscles did not appear to be attached to it. In the nodules there was no trace of retinal neuro-epithelium nor any type of cell other than the fibrous tissue, and a little vascular tissue. Had the usual practice of examining 


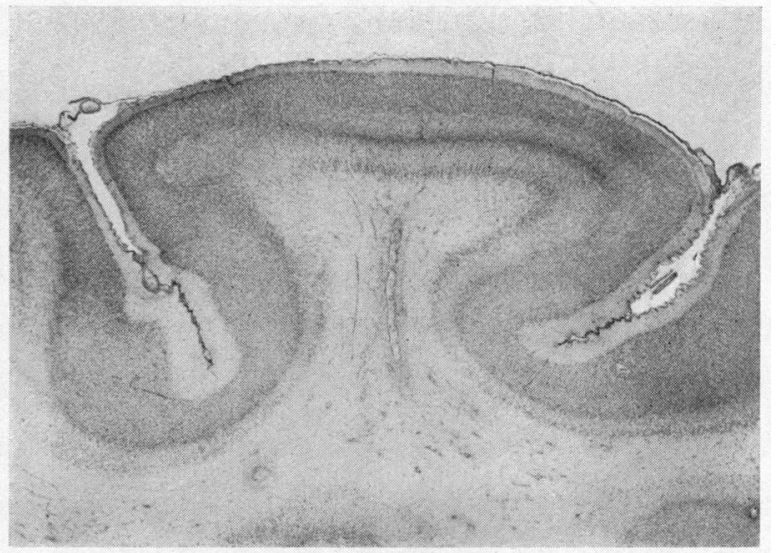

FIG. 6.

Cortex of calcarine region.

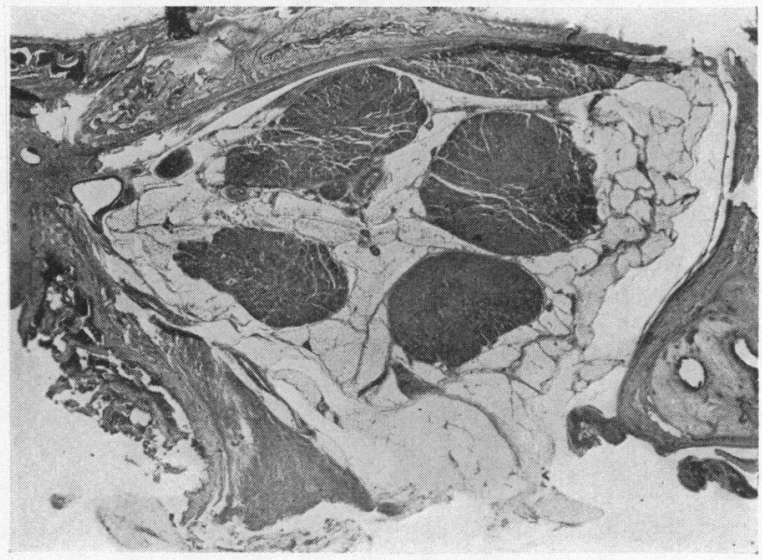

Fig. 7.

Vertical section of left orbit, showing the six extrinsic muscles.

every tenth section been adopted, either of these nodules might well have escaped detection.

This case, we maintain, is a proven one of bilateral primary anophthalmia, where there has been an absolute failure in the development of the optic vesicles, and is distinct from those cases of " degenerative " or " consecutive " anophthalmia in which the vesicles appear to have formed and subsequently to have atrophied. 
(Cases belonging to the latter category have been described by Bietti, Cosmettatos, Haab, Redslob, also Souques and Bertrand.) Such a distinction cannot be made in the majority of the reported cases of this abnormality, since so few are accompanied by microscopical evidence. Cases in which orbital or palpebral cysts are described should not be termed " anophthalmia " of either type. Many reported cases are manifestly ones of extreme microphthalmia.

Perhaps the most conclusive case of primary anophthalmia that we have been able to discover in the literature (excluding the

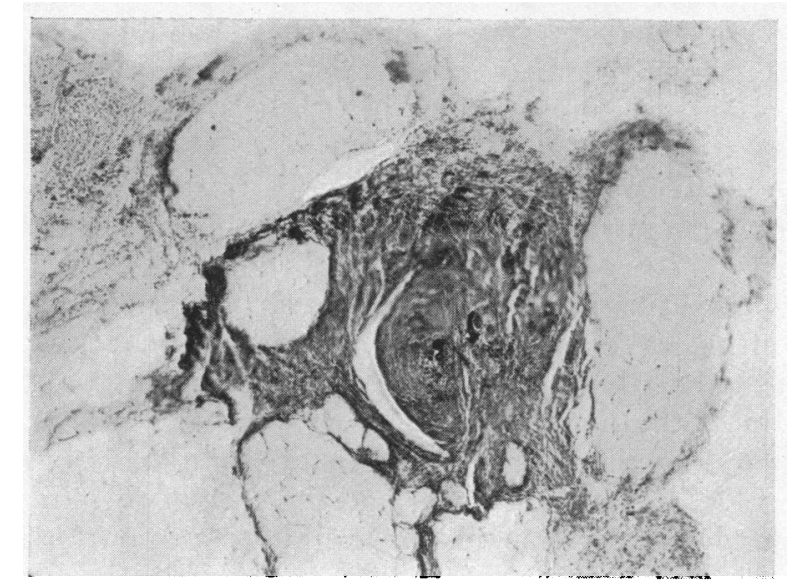

FIG. 8.

Horizontal section of right orbit, showing fibrous nodule with pigment granules.

experimental and animal material) has been reported by Gallemaerts. The child described, a female, survived three months, and the abnormality was familial and hereditary. No trace of any rudimentary element could be discovered in the left orbit, but a heavily pigmented mass, $2.4 \times 0.7 \mathrm{~mm}$. was found in the right. The IVth and VIth cranial nerves were absent and there was irregularity in the position of exit of the IIIrd and Vth.

Van Duyse and Hanke have each reported a case accompanied by details of the orbital contents. Van Duyse found nodules of scleral and choroidal tissue measuring $1 \times 5 \mathrm{~mm}$. in the right orbit and $1 \times 1 \mathrm{~mm}$. in the left, and attached to some of the extrinsic ocular muscles. They appear to be similar to those found in our case, except that there were spaces and cells among the pigment and vessels, with stellate elements. One cannot feel convinced 
that these nodules are entirely of mesodermal origin. In Hanke's case, the transverse section of the bulb rudiment resembles our case, but longitudinally there was a fibrous stalk, sheathed with pigment granules, and running back as far as the foramen.

Spiller, Finkelstein and Shaw Bolton report cases that are probably primary, but examination of the orbits was omitted. The histology of the brain has, however, been carefully worked out ; Finkelstein paying particular attention to the external geniculate bodies which he found present but small, and Shaw Bolton to the calcarine cortex.

Because of the ease with which the optic outgrowth can be suppressed experimentally, Ida Mann believes that more cases should be conceded as "primary" than has been done in the past. The difficulty arises in proving that the pigment found in the orbit is entirely mesodermal in origin.

A nodule representing condensation of scleral tissue and containing minute particles of choroidal pigment is found in experimental primary anophthalmia, and there can be little doubt that the case here reported is one of that condition. The only other abnormalities discovered in this child, who died at the age of two months, were a brain teratoma and a patent foramen ovale. We suggest that the teratoma may have been responsible for the suppression of the optic vesicles.

We are indebted to Dr. J. A. Hislop for details of the family history ; to Dr. Leslie Cole, who had the care of the child whilst in hospital; to Dr. J. F. Gaskell for the autopsy reports, and to $\mathrm{Mr}$. K. Titterington for the photographs of the child and brain. We are also indebted to Dr. J. G. Greenfield for the microphotographs and helpful advice, and to Miss Ida Mann for her interest and suggestions.

\section{REFERENCES}

1. BietTi.-Ann. di Ottal.; Vol. XXX, p. 319, 1901.

2. Bolton, J. S.-Phil. Trans. B., Vol. CXCIII, p. 161, 1900.

3. Cosmettatos, G. F.-Arch. d'Ophtal., Vol. XLVIII, p. 282, 1931.

4. VAN DuYse.-Arch. d'Ophtal.. Vol. XIX, p. 412, 1899.

5. Finkelstein, F.-Schweiz. Arch. f. Neurol. Psych., Voi. XXXVII, p. 16, 1936.

6. Gallemaerts.-Ann. d'Ocul., Vol: CLXI, p. 490, 1924.

7. НАА В, O.-Beitrag. zur Ophthal. Festschr für Horner, p. 131, 1881.

8. HANKE, V.-Arch.f. Ophthal., Vol. LVII. p. 28, 1904.

9. ManN, I.- "Developmental Abnormalities of the Eye," p. 71, 1937. Cambridge University Press.

10. Redslob, E.-Aun. d'Ocul., Vol. CLXIX, p. 133, 1932.

11. Souques, A., and Bertrand, I.-Rev. Neurol., 38 (ii). p. 1, 1931.

12. SPIller, W. G.-Brain, Vol. XXIV, p. 631, 1901. 